\title{
Responding to the Global Pandemic: A Pulse of the Well- Being of Clubhouse Communities Moving Virtual
}

\author{
Amber Michon $(\mathbb{D} \cdot$ Liza Hinchey $\cdot$ Francesca Pernice $\mathbb{D} \cdot$ Jessica Drews • \\ Megan Price $\cdot$ Janay Christian $\cdot$ Kevin Rice $\cdot$ Lee Kellogg
}

Received: 8 January 2021 / Accepted: 8 April 2021/Published online: 21 April 2021

(C) The Author(s), under exclusive licence to Springer Nature India Private Limited 2021

\begin{abstract}
Clubhouse communities rapidly responded to the COVID-19 pandemic to keep members connected as psychosocial rehabilitation programs were globally disrupted. This investigation aims to elucidate how Clubhouse directors responded to the pandemic and their members' needs, while also directly assessing the needs and well-being of members. This study utilized secondary data from Director and Member surveys designed to capture Clubhouse status, member engagement, and measures of wellbeing. Descriptive statistics and correlation coefficients were computed across data from directors $(\mathrm{n}=140)$ and members $(\mathrm{n}=1136)$. Directors across 19 countries indicated that the majority of Clubhouses closed and were engaging with members using a variety of technologies, primarily Zoom videoconferencing. For members, greater levels of virtual Clubhouse engagement were positively correlated with physical and mental well-being and negatively
\end{abstract}

A. Michon $(\varangle) \cdot$ L. Hinchey $\cdot$ F. Pernice

J. Drews · M. Price - J. Christian

351 College of Education, Wayne State University,

Detroit, MI 48202, USA

e-mail: Amber.Michon@wayne.edu

F. Pernice $\cdot$ K. Rice

Fountain House, 425 W 47th St, New York, NY 10036, USA

L. Kellogg

Clubhouse International, 845 Third Avenue, 6th Floor,

New York, NY 10022, USA correlated with hospitalization rates. This study provides support for an association between virtual Clubhouse engagement and well-being. Repeated measures studies are needed to further investigate this association.

Keywords Clubhouse - COVID-19 pandemic . Engagement $\cdot$ Virtual communities $\cdot$ Well-being

\section{Introduction}

Clubhouses, according to Clubhouse International, offer members access to opportunities to rejoin the worlds of friendships, family, employment and education, and to the services and support they may individually need to continue their recovery. A Clubhouse provides a "restorative environment for people whose lives have been severely disrupted because of their mental illness, and who need the support of others who are in recovery and who believe that mental illness is treatable" [1]. Clubhouse communities are generally "places" with "spaces" for people with psychiatric disabilities to engage with others through shared work and roles [2]. However, they have quickly adapted to provide virtual services to their members in response to the COVID-19 pandemic, which forced many Clubhouses to temporarily close. How does a community-based model that operates with small groups and units in a "brick 
and mortar" environment translate that model online and continue to provide a sense of community while facing pandemic conditions? Operating on an approach known as Social Practice, a sense of community is a key factor in promoting recovery of individuals with serious and persistent mental illness (SPMI, [3]). In fact, members overwhelmingly reported social connections and reducing isolation as their top reason for attending a Clubhouse program [4]. With this in mind, Clubhouses responded quickly to the physical distancing mandates put in place to reduce the spread of COVID-19.

Globally, as of June 7th, 2020, there have been $6,799,713$ (1,866,794 U.S.) total confirmed cases of COVID-19 accompanied by 397,388 (109,038 U.S.) total deaths due to COVID-19 [5]. Certainly, this represents a level of risk for all individuals worldwide. However, individuals with SPMI constitute a particularly vulnerable population, though their responses to COVID-19 have been minimally documented. Thus far, research has involved only a limited representation of the many countries experiencing pandemic conditions [6]. Because of the additional mental health concerns related to COVID-19 for the SPMI population and thus Clubhouse members (e.g. inducing fear and isolation onto individuals for which vulnerabilities to fear and isolation are already more apparent) [7-9], the move to a virtual format was conducted swiftly. Given that Clubhouses provide essential services to this population, the abrupt move to a virtual community was not only timely, but necessary. It is hoped that in this and subsequent papers, an understanding of how Clubhouses adapted their virtual formats may be discerned, as well as which strategies in this format appear to be most effective in engaging and protecting their members and this underrepresented, vulnerable population.

\section{Clubhouses as Essential Psychiatric Services}

Clubhouses serve to enhance the quality of life for people with SPMI [10-13], and thus assist in creating spaces for people to develop greater social networks $[2,13]$, cultivate educational and vocational abilities $[14,15]$, and participate in the larger society $[10,12]$. During the COVID-19 pandemic, many people with SPMI, who voluntarily sought the benefits of increased social support and social engagement through Clubhouse participation, were now forced to remain at home-increasing the likelihood of isolation and loneliness (and potentially subsequent hospitalization) among this already at-risk population [7-9]. Further, drawing out individuals who are significantly at-risk for social withdrawal and isolation is at the heart of Clubhouse communities' aims [3, 7]. Therefore, Clubhouses continued to be an essential service during the COVID-19 pandemic for those most at-risk for psychiatric hospitalization.

\section{Study Questions and Objectives}

The purpose of the overall project is to document the essential services of Clubhouses and understand how programs responded to the needs of their membership during specific periods during the pandemic. The objective of the study is to describe the ways in which Clubhouses responded to pandemic and connecting people to services. Further, hospitalization and crises rates were collected during this period to illuminate how Clubhouse connection supported well-being and averting crises during the time period.

\section{Method}

This study involved a secondary analysis of surveys implemented by an international advisory committee consisting of Clubhouse members, staff, directors, and research consultants in collaboration with the faculty from Clubhouse International, the accrediting body for Clubhouse organizations. Institutional review of human subjects was granted to conduct secondary data analysis given the quick turn-around in collecting time-sensitive data during a period of the pandemic affecting much of the global community.

The current investigation involves survey data collected from Clubhouse members and Clubhouse executive directors between April 17th and May 11th, 2020.

\section{Participants}

\section{Clubhouses}

Clubhouse International invited all 309 Clubhouse programs to complete an online survey. From these, a total of 140 Clubhouse executive directors responded and completed the online survey from April 19-May 
22, 2020. Among those who participated, 120 (85.7\%) directors were from accredited Clubhouse programs and 20 (14\%) from non-accredited programs were represented (see Table 1 for a composition of Clubhouses by country). At the time of the survey, only 16 Clubhouses across 5 countries indicated they remained open during the pandemic.

\section{Clubhouse Member Participants}

Again, Clubhouse International invited 309 Clubhouse programs and their members to complete an online survey. Of the 309 Clubhouses invited to participate, members from 140 (45.3\%) Clubhouses completed a Member Survey between April 19-May 22, 2020. Clubhouse members were contacted by their Clubhouse Social Practitioner (i.e., staff) to complete an online survey with assistance. Of the 1869 total Member Survey respondents during the initial measurement, a final sample size of 1136 remained after using listwise deletion to remove cases with missing

Table 1 Clubhouse country participation

\begin{tabular}{lll}
\hline Country & Proportion & $\begin{array}{l}\text { Proportion of clubhouse } \\
\text { participation by } \\
\text { clubhouses } \\
\text { per country }\end{array}$ \\
\hline Belarus & 0.007 & 1 \\
Canada & 0.029 & 0.4 \\
China & 0.007 & 0.25 \\
Denmark & 0.014 & 1 \\
Estonia & 0.007 & 1 \\
Finland & .014 & 0.15 \\
France & 0.014 & 0.67 \\
Germany & 0.014 & 1 \\
Hong Kong (SAR) & 0.007 & 1 \\
India & 0.007 & 1 \\
Ireland & 0.007 & 0.2 \\
Italy & 0.036 & 1 \\
Netherlands & 0.007 & 1 \\
Norway & 0.036 & 0.42 \\
Poland & 0.007 & 1 \\
Russian Federation & 0.007 & 1 \\
South Africa & 0.007 & 1 \\
Sweden & 0.029 & 0.33 \\
United States & 0.743 & 0.52 \\
(U.S.A) & & \\
\hline
\end{tabular}

$n=140$ data. All individual data were de-identified and assigned an ID for data collection and analysis purposes. Member consent was obtained through reading or being read an introduction to the survey containing information about consent and the data usage, after which the participant or interviewer proceeded with the first question as indication of consent. The authors were not active in the data collection process.

\section{Measures}

\section{Clubhouse Survey}

Questions to gather the organizational "pulse" of the Clubhouse consisted of key organizational questions pertaining to funding, staff lay-offs, closure status, membership status (e.g., number of new members/ inactive members, average daily attendance prior to and following COVID-19 closures/quarantine mandates), modality of communication with members prior to and during COVID-19 mandated shutdowns, and general hospitalization estimates (e.g., how many members were hospitalized due to having the virus/ medical/psychiatric conditions during this time?). These questions were designed by the advisory committee in partnership with Clubhouse International. See Table 2 for study questions.

\section{Clubhouse Member Survey}

The Member Survey was typically conducted via an interview format by Clubhouse practitioners. The survey gathered the following information related to the well-being and health during the pandemic: (1) members characteristics, (2) health status, (3) hospitalization visits for medical or psychiatric reasons, (4) employment status, (5) crisis intervention, (6) communication with other Clubhouse members (7) preferred modality of communication, and (8) frequency of virtual engagement with Clubhouses (e.g. daily, weekly, etc.). Further, health questions derived from the Clubhouse Profile Questionnaire (CPQ; [16] assessed the overall self-reported mental and physical health of members during the COVID-19 pandemic. Responses were based on a 10-point scale. See Table 2 for study questions. 


\section{Coping During Quarantine}

Questions assessing the presence or absence of current coping mechanisms were read to participants. Members were asked to indicate the presence or absence of various coping strategies such as maintaining a routine, exercise, leisure activity, contact with friends and family, and various types forms of Clubhouse interaction (e.g., contact with staff, contact with members, and Clubhouse tasks) (Table 3).

\section{Procedures}

All surveys were emailed by the accreditation body of Clubhouses (Clubhouse International) on a weekly scheduled basis over the course of a 6-week period. Institutional Review Board (IRB) exempt human subjects approval was granted through the partner university (IRB-20-04-2040) to assist with secondary data analysis of both surveys. Consent procedures were completed as part of completing the online survey. Clubhouse executive directors completed the survey pertaining to the overall Clubhouse organization. Clubhouse members completed a member's survey with assistance from Clubhouse staff. Member
IDs maintained by Clubhouse staff for follow-up surveys and de-identified data was submitted to the research team.

\section{Data Analysis}

Analyses were conducted using IBM SPSS 26 statistical software and secondary data collected during the initial months of the COVID-19 pandemic (in the U.S.). Regarding the study questions, the following analyses were conducted: (1) univariate descriptive analyses to define sample characteristics and the components/services of the virtual Clubhouses that were most frequently utilized by members, (2) Chisquare likelihood ratios analyses were performed across contingency tables to determine the association between Clubhouse interaction and prevention of crises, and (3) multiple regression was performed on health status self-report and logistic regression analyses performed on the likelihood of psychiatric hospitalization. Diagnostic information was not included in the survey given that Clubhouse members typically must have a diagnosis of a serious and persistent mental illness to participate in most Clubhouses [17].

Table 2 Questions used in the time 1 directors survey

\begin{tabular}{ll}
\hline Location & In which country is your Clubhouse located? \\
$\begin{array}{l}\text { Accreditation } \\
\text { Closure }\end{array}$ & Is your Clubhouse accredited through Clubhouse International? \\
Funding & Did your Clubhouse building close due to COVID-19? \\
& Has your Clubhouse lost funding during the period of COVID-19? \\
& Has your Clubhouse applied for funding during the period of COVID-19? \\
Hembership & Has your Clubhouse received funding in response to COVID-19? \\
& Average daily attendance prior to COVID-19 Clubhouse closure \\
& Number of members your Clubhouse has stayed in contact with since the Clubhouse building closure due to \\
& COVID-19 \\
& How many new members have joined your Clubhouse since the COVID-19 building closure? \\
Haff & How many Clubhouse staff have stopped working (I.e. laid off, fired, etc.) due to COVID-19? \\
Hospitalizations & How many Clubhouse members have been hospitalized for COVID-19? \\
& How many Clubhouse members have been hospitalized for emotional/psychiatric/medical reasons since the onset \\
& of COVID-19? \\
Which of the following did your Clubhouse use to communicate with members prior to the onset of COVID-19?
\end{tabular}

For Time 1, directors were asked to respond to survey questions based on their organizational experiences since COVID-19 Clubhouse closures 
Table 3 Questions used in the time 1 members survey

\begin{tabular}{|c|c|}
\hline \multirow[t]{2}{*}{ Control Variables } & What is the member's age? \\
\hline & What is the member's gender identity? \\
\hline \multirow{6}{*}{$\begin{array}{l}\text { Virtual Clubhouse } \\
\text { Interactions }\end{array}$} & What is their general frequency of attendance? \\
\hline & Is the member receiving enough phone contact from the Clubhouse? \\
\hline & Does the member call other members? \\
\hline & $\begin{array}{l}\text { Coping Mechanisms: What is the member doing that is helping them maintain their physical and mental } \\
\text { wellness? }\end{array}$ \\
\hline & Contact with Clubhouse/Staff \\
\hline & Contact with Members \\
\hline \multirow[t]{5}{*}{ Crisis Questions } & Has the member visited the emergency room? \\
\hline & Type of visit: Medical or Psychiatric \\
\hline & Has the member visited the hospital? \\
\hline & Type of visit: Medical or Psychiatric \\
\hline & $\begin{array}{l}\text { Has the member had a crisis that was prevented by a Clubhouse intervention since your Clubhouse } \\
\text { building closed due to COVID-19? }\end{array}$ \\
\hline \multirow[t]{4}{*}{ Member Well-being } & Current Physical Health: rated from 1 to 10,10 being the best \\
\hline & Physical Health before COVID-19: rated from 1 to 10,10 being the best \\
\hline & Current Mental Health: rated from 1 to 10,10 being the best \\
\hline & Mental Health before COVID-19: rated from 1 to 10,10 being the best \\
\hline Other & Is the member keeping a daily routine? \\
\hline
\end{tabular}

For Time 1, members were asked to respond to survey questions based on their experiences since the COVID-19 closures

\section{Results}

Participant Analyses

\section{Clubhouses}

The Clubhouse Director Survey yielded a $45.3 \%$ $(n=140)$ response rate from the 309 Clubhouses invited to participate worldwide. A total of 19 countries participated in the survey, with most responses presenting from the United States $(74.3 \%)$, followed by Norway (3.6\%), and Italy (3.6\%). The majority of Clubhouses $(n=124)$ reported closing during this time, while a few $(n=16)$ reported remaining open. Directors provided estimates of Clubhouse participation, measured as average daily attendance, before and during the pandemic. Among those Clubhouses that closed during the pandemic, $62.5 \%$ reported having approximately 1-99 members in daily attendance prior to the closures. Following Clubhouse closures, directors and staff reported remaining in steady contact with members.
A total of 137 (97.9\%) Clubhouse directors reported new membership during the pandemic closure and $100(71.4 \%)$ Clubhouses reported contact with inactive Clubhouse members (i.e., at least 90 days without Clubhouse visit) during the same time period. Among the Clubhouses that closed during the COVID-19 pandemic, a total of 33 (26.6\%) directors reported at least one or more staff lay-offs. Regarding funding for Clubhouses during this time, $34.2 \%(n=48)$ of the total sample lost funding, $53.6 \%$ $(n=75)$ applied for financial assistance, and $38.5 \%$ $(n=54)$ reported receiving financial assistance. The quality and type of funding or financial assistance was not delineated. During the pandemic, 118 (84.2\%) Clubhouses reported zero member hospitalizations related to COVID-19 and 54 (38.6\%) Clubhouses reported 1-3 member hospitalizations for psychiatric or other medical reasons. These same Clubhouses were invited to complete a separate survey with their members (see below). Not all Clubhouses that completed the Directors Survey participated in the Members Survey. Therefore, these two surveys are mutually exclusive with the exception of 93 
Clubhouses that completed both the Directors and Member Surveys. This represents $66.4 \%$ of the total sample population of 140 Clubhouses.

\section{Clubhouse Members}

Demographic data was obtained using the member sample size described above during the same time period (Time 1: $n=1136$ ) across 120 Clubhouses that agreed to participate $(38.9 \%)$. Staff assisted in the completion of the online interview with members. See Table 4 for Sample Demographics.

\section{Going Virtual: Communication Modalities}

Prior to the many building closures, communication modalities most often utilized at the Clubhouse, according to the Directors Survey $(n=139)$, were phone calls (100\%), Facebook and Facebook Messenger $(74.8 \%)$, texting/Text Now $(71.2 \%)$, and e-mail $(69.1 \%)$. During the closures, Clubhouses reported the following communication modalities as most frequently utilized: phone calls (98.6\%), texting/Text Now (84.2\%), Facebook and Facebook Messenger (77\%), e-mail (75.5\%), and Zoom (64.7\%). Notably, Zoom communication increased from $8.6 \%$ prior to pandemic closures to $64.7 \%$ during pandemic closures, a $56.1 \%$ change. See Table 5 for all technology usage prior to and during the COVID-19 pandemic closure.

Similarly, the most used modalities of Clubhouse communication, according to the Members Survey ( $n=1136)$ consisted primarily of phone calls $(98 \%)$, texting (57\%), Social Media Applications (Facebook, Snapchat, Instagram, etc.; 43\%), video conferencing (Zoom, Cisco Webex, etc.; 40\%), and e-mail (38\%). Consistent with greater modality usage, the majority of members preferred to communicate via phone calls (93\%) during the initial waves of building closures. At least $60 \%$ reported having Internet access, $60 \%$ reported access to a smart phone, $42 \%$ indicated access to a laptop or tablet computer, and the overwhelming majority (80\%) reported at least having access to a phone.

Among the members, $15 \%$ reported receiving some form of computer/communication technical support. Approximately half of those interviewed indicated a desire for greater contact from their Clubhouse peers as well as personally reaching out to other members.
At least $90 \%$ of the members reported remaining in contact with their Clubhouse peers/community through various online and analog modalities as an important source of coping. On average, participants reported interacting with the virtual Clubhouse on a weekly basis. During the same period, Clubhouse executive directors reported an increase of members who were previously inactive in the Clubhouse prior to the pandemic. Respondents indicated this increase was related to inactive members seeking to rejoin or reach out for support. Inactive membership was defined as members who were not actively involved with Clubhouse activities or had attended the Clubhouse less than once every 90 days.

\section{Barriers to Virtual Communication}

A snapshot of technological barriers was collected among member participants, and at least $50 \%$ of Clubhouse members reported having no barriers to accessing technology resources. Among those reporting barriers, $23 \%$ indicated barriers of equipment cost and $17 \%$ reported barriers of Internet service cost. Additionally, a quarter of the respondents reported a lack of knowledge of how to use technology tools (e.g., setting up Wi-Fi), and about $20 \%$ endorsed a lack of knowledge in using online applications or online meeting programs. During the pandemic, $14 \%$ of members reported that their Clubhouse assisted them in obtaining access to various technology tools, including phones and smartphones, internet, and laptops/tablets.

\section{Clubhouse Community and Health}

\section{Member Health}

Overall, $56 \%$ of Time 1 Member Survey participants were men and $44 \%$ women. From Table 4, half reported living independently $(51 \%)$ and attending the Clubhouse in person weekly (46.6\%) prior to building closures related to the pandemic. Most members reported maintaining a daily routine while in quarantine $(89 \%)$ to assist in adjusting to the many changes the pandemic brought, including the temporary mandated closures of most Clubhouses. Questions pertaining to their health and well-being were assessed before and during the pandemic. Given that several countries were at various stages of the pandemic (e.g., 
Table 4 Member survey sample demographics and preferred communication modalities

\begin{tabular}{|c|c|c|c|}
\hline Variable & Mean/proportion & SD & Range \\
\hline \multicolumn{4}{|l|}{ Member demographics } \\
\hline Age & 46.68 & 13.6 & 61 \\
\hline$\%$ Male & 0.56 & & \\
\hline$\%$ Female & 0.45 & & \\
\hline \multicolumn{4}{|l|}{ Race/Ethnicity } \\
\hline$\%$ White/Caucasian & 0.57 & & \\
\hline$\%$ Hispanic & 0.02 & & \\
\hline$\%$ Black/African American & 0.32 & & \\
\hline$\%$ American Indian/Alaska Native & 0.01 & & \\
\hline$\%$ Asian & 0.008 & & \\
\hline$\%$ Other/Unknown & 0.08 & & \\
\hline \multicolumn{4}{|l|}{ Living Arrangement } \\
\hline$\%$ Independent Housing & 0.51 & & \\
\hline$\%$ With Family & 0.31 & & \\
\hline$\%$ Group Housing & 0.16 & & \\
\hline$\%$ Clubhouse Housing & 0.01 & & \\
\hline$\%$ Shelter & 0.01 & & \\
\hline Member's Clubhouse is Accredited & 0.9 & & \\
\hline Frequency of Clubhouse Attendance & 3.07 & 0.86 & 3 \\
\hline \multicolumn{4}{|l|}{ Member Health } \\
\hline Current Physical Health & 7.47 & 1.89 & 9 \\
\hline Physical Health before COVID-19 & 7.75 & 1.83 & 9 \\
\hline Current Member Health & 7.30 & 2.05 & 9 \\
\hline Member Health before COVID-19 & 7.84 & 1.84 & 9 \\
\hline Emergency Room Visits since Closures & 0.08 & & \\
\hline Psychiatric Emergency Visit & 0.25 & & \\
\hline COVID-19 Emergency Visit & 0.10 & & \\
\hline Hospital Visits since Closures & 0.09 & & \\
\hline Psychiatric Hospital Visit & 0.28 & & \\
\hline COVID-19 Hospital Visit & 0.02 & & \\
\hline Crisis Prevented by Clubhouse Intervention & 0.19 & & \\
\hline \multicolumn{4}{|l|}{ Member Employment During COVID-19 } \\
\hline Full or Partial Loss of Employment & 0.24 & & \\
\hline Receiving Unemployment & 0.05 & & \\
\hline \multicolumn{4}{|l|}{ Member Participation } \\
\hline Participating in Educational Activities & 0.19 & & \\
\hline Participating in a Daily Routine & 0.89 & & \\
\hline \multicolumn{4}{|l|}{ Clubhouse Help and Contact } \\
\hline Received Technology Tools & 0.15 & & \\
\hline Receiving Phone Contact with Clubhouse & 0.95 & & \\
\hline Preferred Frequency of Phone Contact & 2.81 & 0.86 & 4 \\
\hline Calls other Clubhouse Members & 0.52 & & \\
\hline Desire for More Contact with Other Members & 0.48 & & \\
\hline
\end{tabular}


Table 4 continued

\begin{tabular}{|c|c|c|c|}
\hline Variable & Mean/proportion & $\mathrm{SD}$ & Range \\
\hline Utilizing Contact with Staff or Members as Coping Mechanism & 0.89 & & \\
\hline \multicolumn{4}{|l|}{ Member's Preferred Communication Modality } \\
\hline Telephone calls & 0.93 & & \\
\hline Texting & 0.43 & & \\
\hline Emailing & 0.22 & & \\
\hline Facebook & 0.25 & & \\
\hline Messenger & 0.16 & & \\
\hline Snapchat & 0.02 & & \\
\hline Instagram & 0.05 & & \\
\hline YouTube & 0.10 & & \\
\hline Twitter & 0.02 & & \\
\hline TikTok & 0.01 & & \\
\hline HouseParty & 0.01 & & \\
\hline Zoom & 0.22 & & \\
\hline GoToMeeting & 0.02 & & \\
\hline WebEx & 0.02 & & \\
\hline Facetime & 0.07 & & \\
\hline Other & 0.05 & & \\
\hline
\end{tabular}

$n=1136$

Table 5 Communication used with clubhouse members prior to and during COVID-19

$n=139$

\begin{tabular}{lll}
\hline Communication technology & Proportion prior to & Proportion during \\
\hline Phone Calls & 1 & 0.986 \\
Texting/Text Now & 0.712 & 0.842 \\
WhatsApp & 0.122 & 0.158 \\
FaceTime & 0.115 & 0.302 \\
Emailing & 0.691 & 0.755 \\
Fountain House Learning Exchange (LEX) WebEx & 0.072 & 0.122 \\
Skype & 0.065 & 0.101 \\
Zoom & 0.086 & 0.647 \\
GoToMeetings & 0.007 & 0.058 \\
Google Dup & - & 0.050 \\
Google Hangout & 0.014 & 0.108 \\
Slack & 0.007 & 0.072 \\
Discord & 0.022 & 0.072 \\
Facebook and Facebook Messenger & 0.748 & 0.770 \\
Instagram and Instagram Live & 0.245 & 0.273 \\
Twitter & 0.072 & 0.072 \\
Snapchat & 0.036 & 0.036 \\
YouTube & 0.108 & 0.144 \\
House Party & 0.007 & 0.043 \\
Other & 0.128 & 0.307 \\
\hline
\end{tabular}


Italy), experiences of members' self-reported health and well-being are based during the months that the virus initially surged in the U.S. (March-May, 2020).

Members were asked to rate their mental and physical health status both prior to the pandemic closures and during the pandemic period. Ratings were based on a 10-point scale from poor (0) to excellent $(10)$, and responses averaged $7.75(S D=1.83)$ prior to the pandemic and $7.47(S D=1.89)$ during the pandemic for physical health. Mental health selfreported scores averaged $7.84(S D=1.84)$ prior to the pandemic, and $7.3(S D=2.05)$ during. Of all selfreported emergency room visits $(8 \%)$, one-fourth were due to psychiatric emergencies. Approximately $20 \%$ of members received some form of crisis intervention from their respective Clubhouse during the closures.

Members were also asked about the presence of pre-existing health conditions during the interview and $75 \%$ indicated one or more pre-existing conditions, with many conditions falling into the following categories: pulmonary/respiratory disease $(33 \%)$, cardiovascular disease $(39 \%)$, diabetes $(31 \%)$, and obesity $(31 \%)$. Other conditions falling outside these categories included: metabolic syndrome (3\%) and comorbid substance use (5\%).

\section{Staying in Contact with the Clubhouse Community}

In order to determine whether Clubhouse interventions or sustained contact averted crises during their initial pandemic response, Chi-square likelihood ratios were performed. These analyses examined the relationship between the following dichotomous variables: Clubhouse contact (1) member reported calling other members, and (2) member reported contact with Clubhouse members or staff as a coping mechanism) and whether a member reported having had a crisis prevented by Clubhouse intervention. A Chi-square test for independence (with Yates Continuity Correction) indicated no significant relationship between contact with Clubhouse members or staff as a coping mechanism and health crisis prevention, $X^{2}(1$, $n=1136)=0.737, p=0.39$, phi $=0.03$. However, the same analysis testing the association between calling other members and health crisis prevention revealed a significant association between these two variables, $\quad X^{2}(1, \quad n=1136)=15.65, \quad p<0.001$, $p h i=0.12$.

\section{Hospitalization and Contact}

A logistic model was fitted to the data to test the hypothesis regarding the relationship between reports of a hospitalization or emergency room visit and whether they reported Clubhouse contact prior to the hospitalization. Also included in the model as control variables were age, gender, existence of a daily routine during the closure, frequency of Clubhouse attendance, and whether members perceived their phone communication with the Clubhouse as adequate during this period. The authors hypothesized that maintaining contact with the Clubhouse would be predictive of fewer instances of hospitalization or emergency room visits. Members who reported having been in contact with the Clubhouse were $28.8 \%$ less likely to report a hospitalization or emergency room visit compared to those who reported having no Clubhouse contact prior to their hospitalization. Additionally, for every one unit increase in frequency of Clubhouse attendance (e.g. monthly to weekly attendance, weekly to daily attendance), members were $31.3 \%$ less likely to report a hospital or emergency room visit. Females were $60.6 \%$ more likely than males to report any hospitalization during this time period compared to males (Table 6).

\section{Well-Being}

A multiple linear regression was calculated to predict Clubhouse member well-being based on reports of following a daily routine, Clubhouse contact, frequency of Clubhouse attendance, and perceived adequacy of Clubhouse contact, while controlling for age and gender. Member well-being self-reports were obtained for both physical and mental health separately, based on 10-point Likert scales described earlier. The results suggest that females, on average, reported lower physical health well-being scores $(B=-0.387, p<0.01)$ and mental health well-being scores $(B=-0.423, p<0.001)$ compared to males. More frequent attendance at the Clubhouse was predictive of higher self-reports of physical health ( $B=0.16, p<0.05$ ), but not mental health. Only for scores pertaining to mental health well-being did members report higher scores $(B=0.64, p<0.05)$ when they perceived the level of contact from the Clubhouse during the closures as adequate. Finally, as predicted, members who reported following a daily 
Table 6 Summary of logistic regression analyses of variables predicting member hospitalizations

\begin{tabular}{|c|c|c|c|c|c|c|}
\hline \multirow[t]{2}{*}{ Variable } & \multicolumn{3}{|c|}{$\begin{array}{l}\text { Reported hospital or emergency } \\
\text { visit }\end{array}$} & \multicolumn{3}{|c|}{$\begin{array}{l}\text { Reported psychiatric or emergency } \\
\text { visit }\end{array}$} \\
\hline & $B$ & $S E$ & $\operatorname{Exp}(B)$ & $B$ & $S E$ & $\operatorname{Exp}(B)$ \\
\hline Age & -0.009 & 0.007 & 0.991 & $-0.03 *$ & 0.012 & 0.971 \\
\hline Gender $(1$ = female $)$ & $0.474 *$ & 0.187 & 10.606 & 0.572 & 0.330 & 1.771 \\
\hline Daily Routine & -0.16 & 0.273 & 0.852 & -0.466 & 0.434 & 0.627 \\
\hline Clubhouse Contact (1 = Yes) & $-0.339 *$ & 0.273 & 0.712 & -0.538 & 0.504 & 0.584 \\
\hline Frequency of Clubhouse Attendance & $-0.375 * * *$ & 0.101 & 0.687 & -0.082 & 0.189 & 0.921 \\
\hline Receiving Enough Phone Contact from the Clubhouse & -0.315 & 0.372 & 0.73 & 0.808 & 1.03 & 2.242 \\
\hline Constant & 0.124 & 0.621 & 0.884 & -1.924 & 1.337 & 0.146 \\
\hline
\end{tabular}

$n=1136$. Clubhouse contact refers to answering yes to any/all of the following: calls other members, considers contact with members a coping mechanism, considers contact with Clubhouse/Staff a coping mechanism. Additionally, the number of members reporting psychiatric hospitalizations was $40(3.5 \%)$, a low $\mathrm{N}$ which may have impacted the analyses

$* p<0.05 ; * * p<0.01 ; * * * p<0.001$

routine at least most of the time, on average, scored higher on the physical health well-being measure $(B=0.970, p<0.001)$ and on the mental health wellbeing measure $(B=1.252, p<0.001)$ compared to individuals who reported not following a daily routine (Table 7).

\section{Meeting Basic Needs}

Members were asked to report on the status of their basic needs during the weekly member survey. These included the need for the following: assistance from food banks, meal delivery, grocery delivery, transportation, financial needs, medication refills, medical/ psychiatric phone appointments, and medical/psychiatric in-person appointments. For all categories, a majority of participants reported either not having the need or that the need was met. The categories with the highest number of participants reporting their need being unmet were financial needs $(7 \%)$ and in-person medical/psychiatric in-person appointments $(6 \%)$. For all other categories, the probability that the need was unmet was low, ranging from 2 to $5 \%$ of respondents.

\section{Self-reported Coping Mechanisms}

Clubhouse members reported a variety of coping mechanisms that they deemed helpful during the COVID-19 and Clubhouse closures. The majority of participants $(89 \%)$ reported that maintaining a daily routine was most helpful when dealing with the stress from the pandemic. Participants also reported partaking in a variety of active and leisure activities. Among the active activities, taking walks $(68 \%)$, casual exercise $(34 \%)$, meditation $(22 \%)$, and yoga (8\%) were most utilized. Leisure activities, such as watching television (79\%), using social media and other Internet-based applications (50\%), reading (44\%), miscellaneous hobbies $(41 \%)$, and self-motivating projects $(24 \%)$ were deemed most helpful.

Members reported that having consistent communication with their peers and Clubhouse staff also helped them navigate the emotional and psychological hardships brought on by the pandemic. Communication with Clubhouse staff was reported the most utilized ( $85 \%$ ) followed by communication with one's family $(79 \%)$. Communication with other members $(55 \%)$ and friends that had no relation to their Clubhouse (54\%) were also widely reported as great coping mechanisms for members. Staying involved in Clubhouse endeavors, such as projects or daily tasks, was reported by $25 \%$ of members as a helpful coping mechanism during Clubhouse closures.

\section{Discussion}

During the uncertainty that accompanied the COVID19 pandemic, requiring rapid responses and immense flexibility, Clubhouse directors, staff and members were able to provide important details regarding the organizational response of transitioning to a virtual 
Table 7 Summary of multiple regression analyses of variables predicting member well-being

\begin{tabular}{|c|c|c|c|c|c|c|}
\hline \multirow[t]{2}{*}{ Variable } & \multicolumn{3}{|c|}{ Physical Health } & \multicolumn{3}{|c|}{ Mental Health } \\
\hline & $B$ & $S E$ & $95 \% \mathrm{CI}$ & $B$ & $S E$ & $95 \% \mathrm{CI}$ \\
\hline Age & -0.005 & 0.004 & {$[-0.013,0.003]$} & 0.004 & 0.004 & {$[-0.005,0.012]$} \\
\hline Gender ( 1 = female $)$ & $-0.387 * *$ & 0.111 & $\begin{array}{l}{[-0.605} \\
-0.169]\end{array}$ & $-0.423 * * *$ & 0.120 & $\begin{array}{l}{[-0.658} \\
-0.189]\end{array}$ \\
\hline Daily Routine & $0.970 * * *$ & 0.173 & {$[0.631,1.309]$} & $1.252 * * *$ & 0.186 & {$[0.887,1.618]$} \\
\hline Clubhouse Contact & -0.098 & 0.203 & {$[-0.495,0.3]$} & -0.239 & 0.218 & {$[-0.668,0.189]$} \\
\hline Frequency of Clubhouse Attendance & $0.16^{*}$ & 0.064 & {$[0.034,0.286]$} & 0.013 & 0.069 & {$[-0.123,0.149]$} \\
\hline $\begin{array}{l}\text { Receiving Adequate Phone Contact from the } \\
\text { Clubhouse }\end{array}$ & 0.333 & 0.248 & {$[-0.155,0.82]$} & $0.64 *$ & 0.268 & {$[0.114,1.165]$} \\
\hline
\end{tabular}

Clubhouse. For an organization whose model is centered around building community [18], this undertaking was imperative. The results provide a deeper understanding of how the transition to a virtual Clubhouse was experienced and implemented by both members and staff. Overall, responses highlighted the importance of sustaining social contact during closures and "stay at home" orders, realizing that for many members living with SPMI, the Clubhouse community is a lifeline. This was also evident in the number of reported "inactive" members who reached out during periods of quarantine and Clubhouse closures, as nearly $72 \%$ of the directors surveyed reported having members who were previously inactive seek out Clubhouse contact during the pandemic.

During the first period of data collection for the current study, approximately 1869 members completed a survey online or through a phone interview with a Clubhouse staff member. Although this approach was not systemically controlled through standardized training and administration procedures, given the urgency of the study, many of the standardized questions included in the survey were modified from questionnaires that are typically completed by Clubhouse staff and members during yearly data collection from the accreditation body (e.g., Clubhouse Profile Questionnaire; [16]. Thus, Clubhouse staff were likely already familiar with many of the questions as well as with effective interview procedures to obtain such data. Overall, members indicated maintaining a daily routine and positive health, as well as contact with Clubhouse staff and/or peers.
Despite the limitations below, the strengths of the current study can be highlighted as a rapid, global effort in understanding Clubhouse responses to assisting members in virtually connecting with their communities during the pandemic. Participating Clubhouses indicated providing some assistance in helping to acquire access to technology for their members (albeit limited), as well as gaining understanding of coping mechanisms and access to basic needs. The survey was implemented by the international community of Clubhouses who facilitated educational webinars for the global community of clubhouses. In essence, the survey served as intervention at best while also providing directors timely information about their clubhouses and membership.

\section{Limitations}

Following, the results of this study are accompanied by several limitations. This study was conducted in order to understand the swift actions initially taken by Clubhouses located in the U.S., Europe, and Asia in response to the COVID-19 pandemic, which forced many Clubhouses to temporarily close their doors and rapidly translate the underpinnings of the model into a virtual setting. At Time 1, countries and organizations were struggling with how to respond to the crisis while also maintaining ongoing programming and services for hundreds of Clubhouse members who had previously been participating in "brick and mortar" programs. Clubhouse International implemented the 
survey over the course of four months and the results from the first survey are reported here.

Given the quick turnaround during this global crisis, some responses provided by directors reflect estimates. As such, the accuracy of their data is not conclusive. Further, surveys conducted by social practitioners (staff) may also have served as a "point of intervention," thus potentially confounding the level of contact reported by members. However, Clubhouse members reported the level of weekly contact or virtual engagement in Clubhouse activities. One possible distinction between the influence of Clubhouse virtual engagement and the contact related to completing the weekly survey is represented in the finding that higher Clubhouse virtual engagement was associated with decreased likelihood of a hospital or emergency room visit.

During the COVID-19 pandemic, several organizations were collecting data to understand its impact on their members. The Clubhouse model was no different. The results of this study are not intended to be generalizable; that is, they are capturing events during a single point in time without historical precedent. However, it may serve to provide insight as to how Clubhouses initially responded during the first few months of the pandemic and how members were faring. Key leaders in the field joined together to immediately design and conduct a global online survey. Given the crisis, the response rate for Clubhouse directors was $45.3 \%$, and the response rate for member participation was $38.9 \%$, indicating a fair amount of engagement given the circumstances and lack of incentives for participation.

Still, a consideration is also warranted regarding Clubhouse members and Clubhouses that did not participate in the study. Many of the countries were in various stages of the pandemic and social distancing mandates. It may be that Clubhouses that did not respond were dealing with the initial surge of virus during the survey period (March-May 2020). Other countries, such as Italy, were moving toward greater stabilization and recovery, whereas Sweden and Hong Kong did not initially report closures. This may have resulted in a biased sample of those willing and able to respond to the surveys. Although we may not be able to generalize to all Clubhouse programs, this study served as an initial attempt to capture of the organizational pulse of how Clubhouse programs were responding to the pandemic crisis.

\section{Conclusion}

The purpose of this investigation was to assess the extent to which Clubhouse programs responded to the global pandemic and how their community programs were impacted by closures. Overall, executive directors who participated in this survey provided their communities with resources to access Clubhouses virtually, demonstrating that technology usage increased from before the pandemic to during the pandemic. Members who reported consistent contact or connection with the Clubhouse were found to have a greater association to positive member experiences.

\section{Clinical Implications}

Clubhouses operate within "spaces and places" to create community for people recovering from SPMI. During the COVID-19 pandemic, Clubhouse communities have been essential for those seeking to connect with familiar and supportive peers and social practitioners, as evidenced by an increase of executive directors reporting higher rates of inactive members returning to Clubhouses or increased rates of new members joining the virtual communities. At the same time, weekly webinars were conducted between key Clubhouse leaders and Clubhouse International to provide direction and support to members and social practitioners in various parts of the country and world. For the first time, this allowed Clubhouses to operate as a larger global community navigating the COVID19 pandemic experiences together. However, concerns that Clubhouse members may prefer to remain virtual once the U.S. and countries begin re-opening is yet to be demonstrated.

\section{Future Directions}

Follow-up surveys with executive directors and Clubhouse members are currently being conducted. Analyses will involve multiple time points to assess changes over time and the extent to which Clubhouse contact may have mediated a reduction in mental or physical health crises. Given the urgency of responding to the COVID-19 pandemic by quickly transitioning programs and services to virtual or analog platforms (e.g., phone), the inherent limitations of the study include reliability and validity of the data collected by practitioners in the field, and the extent to 
which the data captured the reality of the moment. Independent researchers were not involved in gathering data, as to protect the confidentiality and privacy of Clubhouse members, as well as to decrease additional stressors on an already difficult experience. Further, the act of completing a weekly survey with Clubhouse staff may have offered another point of contact, which may have served as an intervention that enhanced members' well-being.

Future studies (if faced with a similar opportunity) may control these limitations by closely monitoring the level of weekly and daily contact and the types of interactions involved (perhaps adding or refining survey items), potentially involving independent researchers in the data collection processes, ensuring that items on repeated surveys are identical (e.g., demographics), as well as conducting comparisons to similar programs that only contact their members via e-mail or online communications (to assess whether virtual Clubhouses are comparable to typical online health-related services).

\section{Declarations}

Conflict of interest On behalf of all authors, the corresponding author states that there is no conflict of interest.

\section{References}

1. Clubhouse International. What Clubhouses do; 2020. https://clubhouse-intl.org/what-we-do/what-clubhousesdo/

2. Carolan M, Onaga E, Pernice-Duca F, Jimenez T. A place to be: the role of clubhouses in facilitating social support. Psychiatr Rehabil J. 2011;35(2):125-32. https://doi.org/10. 2975/35.2.2011.125.132.

3. Doyle A, Lanoil J, Dudek K. Fountain house: creating community in mental health practice. New York: Columbia University Press; 2013.

4. Pernice FM, Price MH, Rice K. Why we come: clubhouse members seek connection, purpose and meaning. Commun Ment Health J. 2020. https://doi.org/10.1007/s10597-02000685-6.

5. World Health Organization. Coronavirus disease (COVID2019) situation report $139 ; 2020$, June. https://www.who. int/emergencies/diseases/novel-coronavirus-2019/ situation-reports

6. Rajkumar RP. COVID-19 and mental health: a review of the existing literature. Asian J Psychiatr. 2020;52:1-5. https:// doi.org/10.1016/j.ajp.2020.102066.
7. Chang CW, Chung CL, Biegel DE, Pernice-Duca F, Min MO, D'Angelo L. Predictors of loneliness of clubhouse members. Psychiatr Rehabil J. 2014;37(1):51-4. https://doi. org/10.1037/prj0000052.

8. Perese EF, Wolf M. Combating loneliness among persons with severe mental illness: social network interventions' characteristics, effectiveness, and applicability. Issues Ment Health Nurs. 2005;26(6):591-609. https://doi.org/10.1080/ 01612840590959425.

9. Prince JD, Oyo A, Mora O, Wyka K, Schonebaum AD. Loneliness among persons with severe mental illness. J Nerv Ment Dis. 2018;206(2):136-41. https://doi.org/10. 1097/NMD.0000000000000768.

10. Gold PB, Macias C, Rodican CF. Does competitive work improve quality of life for adults with severe mental illness? Evidence from a randomized trial of supported employment. J Behav Health Serv Res. 2016;43(2):155-71. https:// doi.org/10.1007/s11414-014-9392-0.

11. McKay C, Nugent KL, Johnsen M, Eaton WW, Lidz CW. A systematic review of evidence for the clubhouse model of psychosocial rehabilitation. Admin Policy Mental Health Mental Health Serv Res. 2018;45(1):28-47. https://doi.org/ 10.1007/s 10488-016-0760-3.

12. Tsang AW, Ng RM, Yip KC. A six-month prospective casecontrolled study of the effects of the clubhouse rehabilitation model on Chinese patients with chronic schizophrenia. East Asian Arch Psychiatry. 2010;20(1):23-30.

13. Warner R, Huxley P, Berg T. An evaluation of the impact of clubhouse membership on quality of life and treatment utilization. Int J Soc Psychiatry. 1999;45(4):310-20. https:// doi.org/10.1177/002076409904500410.

14. Mowbray CT, Holter MC, Mowbray OP, Bybee D. Consumer-run drop-in centers and clubhouses: comparisons of services and resources in a statewide sample. Psychol Serv. 2005;2(1):54-64. https://doi.org/10.1037/1541-1559.2.1. 54.

15. Schonebaum A, Boyd J. Work-ordered day as a catalyst of competitive employment success. Psychiatr Rehabil J. 2012;35(5):391-5. https://doi.org/10.1037/h0094499.

16. Clubhouse International. Clubhouse Profile Questionnaire; 2012. http://clubhouse-intl.org/images/download_discuss_ cpq.pdf retrieved July 13, 2020

17. Clubhouse International. FAQ; 2020. https://clubhouse-intl. org/what-we-do/faq/

18. Fang-pei C. Building a working community: staff practices in a clubhouse for people with severe mental illness. Admin Policy Mental Health Mental Health Serv Res. 2017;44(5):651-63. https://doi.org/10.1007/s10488-0160757-y.

Publisher's Note Springer Nature remains neutral with regard to jurisdictional claims in published maps and institutional affiliations. 